\title{
A Study on Sub-Clinical Narcissistic Personality Score and Its Relationship with Academic Performance-An Indian Experience
}

\author{
Vaidhyanatha Balaji $1^{1} \&$ Indradevi Balasundaram ${ }^{1}$ \\ ${ }^{1}$ VIT Business School, VIT University, Vellore, India \\ Correspondence: Indradevi Balasundaram, VIT Business School, VIT University, Vellore, Pin Code 632014, \\ Tamilnadu, India. Tel: 91-97-9169-3332. E-mail: rindradevi@vit.ac.in
}

Received: July 14, 2014 Accepted: October 28, 2014 Online Published: December 20, 2014

doi:10.5539/ass.v11n2p96

URL: http://dx.doi.org/10.5539/ass.v11n2p96

\begin{abstract}
Sub-clinical narcissism is the presence of narcissistic personality traits in otherwise normal people. People with high levels of these traits said to have inflated self-esteem and possibly a high egotism. A 40 itemed Narcissistic Personality Inventory is used to measure this type of personality traits. Those individuals who score above 20 points from the available 40 points of NPI-40 Inventory is considered to be having higher levels of Subclinical Narcissism and prone to exhibit socially dislikeable personality traits. This study tried to address the relationship between supposedly negative personality traits of Sub-clinical Narcissism using NPI-40 Score against past and present academic performance of a group of students in a Private University setup. The study included 202 participants from a Business School Division of a Private University. Analysis showed that only at the current academic levels of the respondents, NPI-40 scores were significantly correlating with their academic performance. Research implications are discussed.
\end{abstract}

Keywords: academic performance, negative personality traits, npi-40, personality psychology, social psychology, subclinical narcissism

\section{Introduction}

Narcissism-The term Narcissism comes from a tragic story of Greek Mythology about a youth named Narcissus, who fell in love with his own image reflected in a pool of water and started getting obsessed by it to the extent where he died in the end looking at it for weeks and months. Currently, Narcissism as a term is used in Personality Psychology to describe a socially disruptive personality trait that is characterized by a grandiose self-view, a sense of entitlement, lack of empathy, and egotism. Although most individuals have some form of narcissistic traits, high levels of narcissism can manifest themselves in a pathological form as Narcissistic personality disorder (NPD), in which the individual is described as being excessively preoccupied with issues of personal adequacy, power, prestige and vanity

On the other side, Subclinical (clinically not significant) Narcissism is not seen as Pathological Personality disorder by Clinical Psychologists. But it has got few offensive behavioral traits that are on many occasions not socially acceptable. They are, Grandiose Self-Views, Exhibitionism, Entitlement, Exploitativeness, Superiority, Authority, and Self-Sufficiency. These constructs are the areas of interest for many of the social-psychology researchers. Based on various studies, Researchers have developed this set of constructs that supposed to make Subclinical Narcissism traits on an individual. Long considered as a negative personality trait in a society that is increasingly becoming competitive in all aspects of life. How such a negative personality trait act upon some of the critical parts of an individual's growth as a person in a society is an area that is gaining lots of interest in the recent times among social psychologists.

Personality Traits and Academic Performance-Do personality traits of individual determine their academic performance at various stages of their school/college life? While researchers from the past has shown Big five personality traits such as Openness to experience, Conscientiousness, Extroversion, Agreeableness, and Neuroticism to be of having some relation to school performance (e.g., Costa \& McCrae, 1992; De Raad, 1996), academic success is still seen by many researchers as a function of intellectual ability than personality (Rothstein, Paunonen, Rush, \& King, 1994) and (Allik \& Realo, 1997). Though there are many studies conducted in the field of Personality as a predictor for individual's college performances (Wolfe \& Johnson, 1995), there are very few studies which examined negative personality traits relationship with academic achievement. Most of the 
current studies in this domain focuses on testing the relationship between personality traits and Academic performance of individuals, with Big Five Personality traits as the predictor for academic and work place performance (Chomorro-Premuzic \& Furnham, 2003a/b) and (Higgins, Peterson, Pihl, \& Lee, 2007). Conscientiousness in particular has been the widely studied personality trait as the predictor for individual's academic achievement (Wagerman \& Funder, 2007). In this scenario, this study tries to understand the relationship between Negative Personality Trait such as Subclinical Narcissism and Academic performance of individuals over the years.

\section{Literature Review}

Research on personality and its relationships to important personal, social and economic constructs is as vibrant and influential as ever (Funder, 2001) and has been credited with prompting major advances in the field of organizational behavior (Hough, 2001). Much of this contribution can be linked directly to theoretical and statistical reviews of the role of personality, such as the pivotal meta-analyses of correlations between personality and work performance (Barrick \& Mount, 1991; Hough, Eaton, Dunnette, Kamp, \& McCloy, 1990). This inter-disciplinary approach towards personality and its impact on individual's growth have allowed researchers to assess the major features of these relationships, providing path for future studies. While there are many studies on positive personality traits and its relationship with academic performance, there has been no comparable review of the relationship between personality traits that are considered negative and academic performance.

One of the earliest applications of trait-based personality assessment was the prediction of academic performance. Webb (1915) and Spearman (1927), proposed factors such as "Will" and "General Intelligence" as the contributors for improved academic ability. Similarly, Flemming et al. (1932) found that personality measures were indeed correlating with academic performance. Unfortunately, most of the early researches were plagued by inconsistent research findings and methodological discrepancies. In one of the earliest reviews in this field, Harris (1940) expressed the view that personality contributed to academic performance, but acknowledged that this was unsupported by evidence because research up to that point was marred by inconsistent and flawed methodologies. Later, Stein (1963) emphasized the difficulty of making sense of research based on diverse theories and measures, while Margrain (1978) noted much creativity in methodology, but findings that showed no clear trends. The next major review in this field by De Raad \& Schouwenburg (1996) highlighted the scattered nature of this research and its lack of an overarching framework or paradigm, while Farsides and Woodfield (2003) concluded that findings in this area of research had been "erratic". In brief, reviews of research on the relationship between personality and academic performance have generally presented equivocal conclusions, largely due to the use of variable research methodologies and theoretical bases.

Subclinical Narcissism is also found to be important part of an unholy trinity known as the Dark Triad of Personality Traits (Paulhus \& Williams, 2002) and (Jonason \& Webster, 2012) that includes Machiavellianism, Subclinical Psychopathy involving individuals to have a callous-manipulative interpersonal characteristics and are aversive to long-term relationships. Kohut $(1966,1968,1971,1972)$ has written extensively on narcissism and like Freud (1914/1991) he too believed that narcissism was a healthy and normal part of development and "neither pathological nor obnoxious" (1966, p. 243).

Clinical theory and research has informed the empirical study of narcissism by personality and social psychologists. They see narcissism as a personality trait existing at the sub-clinical level in normal populations. While Subclinical (Borderline) Narcissism is not seen as Pathological Personality disorder by Clinical Psychologists, it still got few offensive behavioral traits which on occasions not socially acceptable. Raskin and Hall (1979) developed a set of constructs that supposed to lead to Subclinical Narcissistic traits on individuals. They are, Grandiose Self-Views, Exhibitionism, Entitlement, Exploitativeness, Superiority, Authority, and Self-Sufficiency. Raskin \& Hall (1979) developed the Narcissistic Personality Inventory based on the DSM-III criteria for Narcissistic Personality Disorder, and later revised it to its current 40-item forced-choice version (Raskin \& Terry, 1988). This is the most widely used scale in narcissism research. The full NPI is positively correlated with clinical ratings of narcissism (Prifitera \& Ryan, 1984), indicating that while we call these subjects 'sub-clinical' that may be because some of them have not sought treatment. The NPI measures narcissism as a continuous variable and there is no specific cut off score for which a person would be considered a clinical narcissist (Foster \& Campbell, 2007).

Social Scientists Stephen Horvath \& Carolyn Morf (2009), Giovanni Maria Ruggiero et al. (2011) have found out from their studies that an Individual's Narcissistic Personality traits in general are result of a person's subconscious Low Implicit Self-Esteem, usually associated with the protection of a radically weak, shamed, or 
damaged self. Peter Jonson and Gregory Webster (2012) study found out that in some individuals Subclinical Narcissism can also be part of an unholy trinity known as the Dark Triad of Personality Traits that includes Machiavellianism, Subclinical Psychopathy. Narcissistic traits and its relationship with individual's academic and professional success is an area which could throw more light onto Subclinical Narcissism. There is a lacuna on how a person with higher levels of subclinical narcissism performs in a social environment where his/her growth depends on academic performance. This is where studying a socially disliked yet clinically non-pathological form of personality trait such as Narcissism comes into play. Scope of this article limits itself to studying the levels of Subclinical Narcissism, and its relationship with Academic performance of students during various stages of their academic levels.

\section{Research Objectives}

1) To measure the Subclinical Narcissistic score of college graduates

2) To test the relationship between Subclinical Narcissistic Score and Academic Performance over the years (both past and present academic performance)

\subsection{Hypotheses}

The previous review of extant research supports linkages between Personality traits and the Academic Performance of students, thus lending support to a set of testable hypotheses. NPI-40 score is positively related with each of the four academic levels of college students: Secondary (10th Standard) grade (Hypothesis 1), Higher Secondary (12th standard) grade (Hypothesis 2), Under Graduate Degree grade (Hypothesis 3), and Post Graduate Degree grade (Hypothesis 4).

\section{Methodology}

A cross-sectional survey was undertaken for the purpose of studying the statistical relationships between NPI-40 score, and Academic Performance of college level students.

\subsection{Population and Sample Selection}

Population for this study was first and final year Master Degree students of Business Administration from a Business school division of a reputed private university, who are well versed in Basic English language comprehension. There were 2000 students in total (mix of male and female students), out of which 202 students were selected using convenience sampling method. This equates to $10 \%$ of the total population.

\subsection{Participants and Procedures}

Participants were the current students of Master of Business Administration from a well reputed a Private University. Survey Questionnaires were completed in a series of five mass-testing sessions in a large lecture hall. Once participants completed the measures, they were debriefed and thanked for participating. The participants received neither remuneration nor any material benefit for the completion of questionnaires.

\section{Measures}

Subclinical Narcissism-Subclinical Narcissism was measured using the Narcissistic Personality Inventory (NPI; Raskin \& Hall, 1979, 1981). The NPI was developed according to diagnostic criteria but provides an index of narcissism that reflects both pathological levels as well as less extreme forms that reflect narcissism as a personality trait. It measures global narcissism and its components. We used the 40 -item version (Raskin \& Terry, 1988). Research demonstrates adequate reliability and validity of the NPI in adults (Raskin \& Terry, 1988, pp. 890-893). The construct validity and internal consistency of the NPI has been previously demonstrated (Emmons, 1987; Raskin \& Hall, 1981; Raskin \& Terry, 1988). For the present study, the internal consistency of this measure was adequate, $\mathrm{a}=0.787$.

Academic Performance-Participants were asked to provide their past and present grades in Academics starting from their Secondary (10th standard) education through Higher Secondary (12th standard), Under Graduate Degree till their current Master's Degree program in percentages.

\section{Results}

\subsection{Demographic Details of the Participants}

Around 33 percentage of the participants were from Final Year of their Master's Degree in Business Administration (MBA) while the remaining 67 percentage were in 1st Year of their MBA studies. 56 percentage of the respondents were male, while remaining 44 percentage were female, aged between 22-26 years (Mean Age $=23.22, \mathrm{SD}=1.26$ ) 
Table 1. Sub-clinical narcissistic score of participants

\begin{tabular}{lll}
\hline NPI-40 Score & No of Respondents & Percentage \\
\hline 15 and less than 15 & 49 & 24.25 \\
Between 16 to 19 & 51 & 25.24 \\
20 and above & 102 & 50.49 \\
\hline
\end{tabular}

Research Objective of measuring Sub-Clinical Narcissistic Score of test subjects were completed using NPI-40 Inventory. Table 1 shows that over $50 \%$ of the respondents of having NPI-40 scores equal to or in excess of 20 with a mean of 19.35 and Standard Deviation of 5.95. According to Raskin \& Hall (1979), Raskin \& Terry (1988), NPI-40 scores of 10 to 15 is generally found in normal population. NPI-40 Scores found in between 15 and 20 are said to be borderline. Those respondents who have NPI-40 score equal to or in excess of 20 is considered to be having a highly Narcissistic Personality albeit without any pathological connotation (Subclinical). This suggests that there is a considerable amount of Subclinical Narcissistic Tendencies is displayed over the response of the test subjects.

Table 2. Descriptive statistics of academic performance and NPI-40 score

\begin{tabular}{llllll}
\hline & N & Minimum & Maximum & Mean & Std. Deviation \\
\hline Secondary Performance & 202 & 42 & 95 & 76.33 & 9.596 \\
Higher Secondary Performance & 202 & 43 & 97 & 78.71 & 9.012 \\
UGD Performance & 202 & 42 & 93 & 76.7 & 7.678 \\
PGD Performance & 202 & 43 & 89 & 76.36 & 6.981 \\
NPI 40 Score & 202 & 6 & 33 & 19.35 & 5.95 \\
\hline
\end{tabular}

Table 2 shows that chosen participants were having consistently above average academic performance over the various stages of their academic years with only marginally maximum performance being observed during their higher secondary years (Mean 78.71 with a standard deviation of 9.012) and marginally lowest performance during secondary school years (Mean 76.33 with a standard deviation of 9.596).

Table 3. Correlations between NPI-40 and academic performance

\begin{tabular}{lllllll}
\hline & & NPI 40 & Sec & Hr.Sec & UGD & PGD \\
\hline NPI 40 Score & Pearson Correlation & 1 & 0.083 & 0.077 & 0.086 & $.164^{*}$ \\
& Sig. (2-tailed) & & 0.243 & 0.278 & 0.224 & 0.02 \\
Sec Performance & Pearson Correlation & 0.083 & 1 & $.215^{* *}$ & 0.001 & $.260^{* *}$ \\
& Sig. (2-tailed) & 0.243 & & 0.002 & 0.99 & 0 \\
High Sec Performance & Pearson Correlation & 0.077 & $.215^{* *}$ & 1 & 0.003 & 0.107 \\
& Sig. (2-tailed) & 0.278 & 0.002 & & 0.961 & 0.131 \\
UGD Performance & Pearson Correlation & 0.086 & 0.001 & 0.003 & 1 & 0.086 \\
& Sig. (2-tailed) & 0.224 & 0.99 & 0.961 & & 0.222 \\
PGD Performance & Pearson Correlation & $.164^{*}$ & $.260^{* *}$ & 0.107 & 0.086 & 1 \\
& Sig. (2-tailed) & 0.02 & 0 & 0.131 & 0.222 & \\
& N & 202 & 202 & 202 & 202 & 202 \\
\hline
\end{tabular}

*. Correlation is significant at the 0.05 level (2-tailed).

**. Correlation is significant at the 0.01 level (2-tailed).

Hypotheses. A series of hypotheses were advanced earlier in this paper, all in reference to the various relationships between NPI-40 Score and Academic Performance of Students. The correlations used to test these hypotheses are presented in Table 3.

$H_{I}$-The first hypothesis suggested that overall NPI-40 Score and 10th standard (Secondary) Academic 
Performance of students are positively and significantly related. This hypothesis was only partially supported $(\mathrm{r}=.083, \mathrm{p} .243)$ with no statistical significance at p. 0.05 level.

$\mathrm{H}_{2}$-The second hypothesis stated that overall NPI-40 score would share a positive, significant relationship with 12th standard (Higher Secondary) Academic Performance of students. This hypothesis was only partially supported ( $\mathrm{r}=0.77, \mathrm{p} .278)$ with no statistical significance at $\mathrm{p} .0 .05$ level.

$H_{3}$-Third hypothesis suggested that NPI-40 score and Academic Performance at Under Graduate degree (UGD) level would share a positive relationship. This hypothesis was only partially supported $(r=0.086, p .224)$ with no statistical significance at p. 0.05 level.

$\mathrm{H}_{4}$-Fourth and final hypothesis suggested that there is a positive and significant relationship between NPI-40 score and Student's Academic Performance at Post Graduate (PGD) level. This hypothesis was fully supported $(\mathrm{r}=0.164, \mathrm{p} .020)$ with statistical significance at p.0.05 level. Additionally, there was also strong positive correlation between 10th standard performance, and 12th standard performance $(r=0.215, \mathrm{p} .0 .02)$ with statistical significance at less than p.005 level. 10th standard performance and PGD Performance (r=.260, p. <0.01) with statistical significance at less than p.001 level. These results support the hypothesis of a positive linear relationship between a student's Subclinical Narcissistic score and his or her Academic Performance but only at higher academic levels it is of statistically significant.

\section{Findings}

Prior to conducting the analyses, the data was screened for the common assumptions of normality and randomness of the sample. There were weak positive correlations between NPI-40 scores and the past academic performance scores of the respondents that include their $10^{\text {th }}$ standard, $12^{\text {th }}$ standard, and Under Graduate Degree academic grades in percentage. But there is a statistically significant strong positive correlation between the student's Post Graduate Degree Performance and NPI-40 Score. Correlation between the academic performance and NPI-40 scores of students are presented as descriptive statistics in Table 1,2 and 3 along with bivariate correlation statistics

\section{Implications for Research and Practice}

Results of this study suggest that there is a wider scope for further exploration in the area of Narcissistic Personality and Academic success. Measuring Subclinical Narcissistic Traits during admission process at the higher levels of education might shed more light on this. Being always perceived as a negative trait, Narcissism could also be the answer for competitive mentality among students of higher studies in the areas of Business Administration. This study can be further expanded to the realms of Professional success of Narcissistic Individuals along with their academic achievement. NPI-40 inventory could be used as one of the pre-assessment tool both at academic and corporate entry level for selection of right candidates.

\section{Limitations of This Study}

We have adapted an unmodified version of NPI-40 questionnaire against non-native English language speakers. This could be accounted for some of the respondent's error while filling the questionnaire as well as lower internal consistency value (Cronbach, 1951) in the form of Cronbach's alpha value of a $=0.787$. Similarly, the context in which the study has been conducted is vastly different from what the adapted questionnaire is intended for (Nunnaly, 1978). This may lead to external validity errors. Hence generalization of this study's results is not advisable.

\section{Conclusion}

The present study demonstrated a link between subclinical narcissism score measured by NPI-40 inventory and academic performances of students at college level. Further, this study investigated the past academic performance against subclinical narcissistic measure and identified, weak yet positive association between academic performance and subclinical narcissistic score. This reflects fluid nature of Personality Measures at various academic levels (Rose \& Campbell, 2004). This fluidity of Narcissistic Personality should be accounted for while studying relationships between various variables. In summary, there is variety of different theoretical perspectives on narcissism, and there is much to be done to resolve many of the controversies in the field of narcissism research. Perhaps the most important point we wanted to make by conducting this study is that we believe presence of high levels of subclinical narcissistic traits should be considered as neither entirely normal nor abnormal (Campbell \& Foster, 2007). Rather, we believe that the consequences of such traits are largely dependent upon the context in which they have been studied and the outcome variables that are assessed, with narcissism being associated with positive outcomes in certain contexts like academic performance in this study. To further this study, rest of the dark triad traits (Machiavellianism, and Subclinical Psychopathy) could also be 
measured to see their relationship with academic and work performance of individuals.

\section{References}

Allik, J., \& Realo, A. (1997). Intelligence, academic abilities, and personality. Personality \& Individual Differences, 23(5), 809-814. http://dx.doi.org/10.1016/S0191-8869(97)00103-7

Barrick, M. R., \& Mount, M. K. (1991). The big five personality dimensions and job performance: A meta-analysis. Personality Psychology, 44, 1-26. http://dx.doi.org/10.1111/j.1744-6570.1991.tb00688.x

Campbell, W. K., \& Foster, J. D. (2007). The narcissistic self: Background, an extended agency model, and ongoing controversies. In C. Sedikides, \& S. J. Spencer, (Eds.), The self: Frontiers of social psychology (pp. 115-138). New York: Psychology Press.

Chomorro-Premuzic, T., \& Furnham, A. (2003a). Personality predicts academic performance: Evidence from two longitudinal university samples. Journal of Research in Personality, 37(4), 319-338. http://dx.doi.org/10. 1016/S0092-6566(02)00578-0

Chomorro-Premuzic, T., \& Furnham, A. (2003b). Personality traits and academic examination performance. European Journal of Personality, 17(3), 237-250. http://dx.doi.org/10.1002/per.473

Costa, P., \& McCrae, R. (1992). Revised NEO personality inventory (NEO-PI-R) and NEO Five-factor inventory (NEO-FFI): Professional manual. Odessa: Psychological Assessment Resources, Inc.

Cronbach, L. J. (1951). Coefficient alpha and the internal structure of tests. Psychometrika, 16, 297-334. http://dx.doi.org/10.1007/BF02310555

De Raad, B. (1996). Personality traits in learning and education. European Journal of Personality, 10(3), 185-200. http://dx.doi.org/10.1002/(SICI)1099-0984(199609)10:3<185::AID-PER256>3.0.CO;2-M

De Raad, B., \& Schouwenburg, H. C. (1996). Personality in learning and education: A review. European Journal of Personality, 10, 303-336. http://dx.doi.org/10.1002/(SICI)1099-0984(199612)10:5<303::AID-PER $262>3.0 . \mathrm{CO} ; 2-2$

Farsides, T., \& Woodfield, R. (2003). Individual differences and undergraduate academic success: The roles of personality, intelligence, and application. Personality and Individual differences, 34(7), 1225-1243. http://dx.doi.org/10.1016/S0191-8869(02)00111-3

Flemming, E. G. (1932). College achievement, intelligence, personality, and emotion. Journal of Applied Psychology, 16(6), 668-674. http://dx.doi.org/10.1037/h0072176

Foster, J. D., \& Campbell, W. K. (2007) Are there such things as "Narcissists" in social psychology? A taxometric analysis of the Narcissistic Personality Inventory, Personality and Individual Differences, 43, 1321-1332. http://dx.doi.org/10.1016/j.paid.2007.04.003

Freud, S. (1914/1991). On narcissism: An introduction. In J. Sandler, E. Person, \& P. Fonagy (Eds.), Freud's “On Narcissism: An Introduction”. Yale University Press, New Haven.

Funder, D. C. (2001). Personality. Annual Review of Psychology, 52, 197-221. http://dx.doi.org/10.1146/annurev. psych.52.1.197

Harris, D. (1940). Factors affecting college grades: A review of the literature, 1930-1937. Psychological Bulletin, 37(3), 125-166. http://dx.doi.org/10.1037/h0055365

Higgins, D. M., Peterson, J. B., Pihl, R. O., \& Lee, A. G. M. (2007). Prefrontal cognitive ability, intelligence, big five personality, and the prediction of advanced academic and workplace performance. Journal of Personality and Social Psychology, 93(2), 298-319. http://dx.doi.org/10.1037/0022-3514.93.2.298

Horvath, S., \& Morf, C. K. (2009) Narcissistic Defensiveness: Hypervigilance and avoidance of worthlessness. Journal of Experimental Social Psychology, 45, 1252-1258. http://dx.doi.org/10.1016/j.jesp.2009.07.011

Hough, L. M. (2001). I/Owes its advances to personality. In B. W. Roberts (Ed.), Personality psychology in the workplace: Decade of behavior (pp. 19-44). Washington, DC: American Psychological Association. http://dx.doi.org/10.1037/10434-001

Hough, L. M., Eaton, N., K., Dunnette, M. D., Kamp, J. D., \& McCloy, R. A. (1990). Criterion-related validities of personality constructs and the effect of response distortion on those validities. Journal of Applied Psychology, 75(5), 581-595. http://dx.doi.org/10.1037/0021-9010.75.5.581

Jonason, P. K., \& Webster, G. D. (2012). A protean approach to social influence: Dark Triad Personalities and 
social influence tactics. Personality and Individual Differences, 52, 521-526. http://dx.doi.org/10.1016/j. paid.2011.11.023

Kohut, H. (1966). Forms and transformations of narcissism. Journal of the American Psychoanalytic Association, 14, 243-272. http://dx.doi.org/10.1177/000306516601400201

Kohut, H. (1968). The psychoanalytic treatment of narcissistic personality disorders: Outline of a systematic approach. The psychoanalytic Study of the Child, 23, 86-113.

Kohut, H. (1971). The analysis of the self: A systematic approach to the treatment of Narcissistic personality disorders. Madison, CT: International Universities Press.

Kohut, H. (1972). Thoughts on narcissism and narcissistic rage. The psychoanalytic Study of the Child, 27, 360-400.

Margrain, S. A. (1978). Student characteristics and academic performance in higher education: A review. Research in Higher Education, 8(2), 111-123. http://dx.doi.org/10.1007/BF00992113

Nunnaly, J. (1978). Psychometric theory. New York: McGraw-Hill.

Paulhus, D., \& Williams, K. (2002). The Dark Triad of Personality: Narcissism, Machiavellianism, and Psychopathy. Journal of Research in Personality, 36, 556-563. http://dx.doi.org/10.1016/S0092-6566(02) 00505-6

Prifitera, A., \& Ryan, J. J. (1984). Validity of the Narcissistic Personality Inventory (NPI) in a psychiatric sample. Journal of Clinical Psychology, 40, 140-142. http://dx.doi.org/10.1002/1097-4679(198401)40:1<140:: AID-JCLP2270400127>3.0.CO;2-E

Raskin, R., \& Hall, C. S. (1979). A narcissistic personality inventory. Psychological Reports, 45, 590. http://dx.doi.org/10.2466/pr0.1979.45.2.590

Raskin, R., \& Terry, H. (1988). A principal-components analysis of the Narcissistic Personality Inventory and further evidence of its construct validation. Journal of Personality and Social Psychology, 54, 890-902. http://dx.doi.org/10.1037/0022-3514.54.5.890

Rose, P., \& Campbell, W. K. (2004). Greatness feels good: A telic model of narcissism and subjective well-being. In S. P. Shohov (Ed.), Advances in psychology research (Vol. 31, pp. 3-26). Hauppauge, NY: Nova Science Publishers.

Rothstein, M., Paunonen, S., Rush, J., \& King, G. (1994). Personality and cognitive ability predictors of performance in graduate business school. Journal of Educational Psychology, 86(4), 516-530. http://dx.doi.org/10.1037/0022-0663.86.4.516

Spearman, C. (1927). The abilities of man. London: Macmillan.

Stein, M. I. (1963). Personality measures in admissions: Antecedents and personality factors as predictors of college success. New York: College Entrance Examination Board.

Wagerman, S., \& Funder, D. (2007). Acquaintance reports of Personality and Academic Achievement: A case of conscientiousness. Journal of Research in Personality, 41, 221-229. http://dx.doi.org/10.1016/j.jrp.2006. 03.001

Webb, E. (1915). Character and Intelligence: An Attempt at an Exact Study of Character. Cambridge, U.K.: Cambridge University Press.

Wolfe, R., \& Johnson, S. (1995). Personality as a predictor of college performance Educational \& Psychological Measurement, 55(2), 177-185. http://dx.doi.org/10.1177/0013164495055002002

\section{Copyrights}

Copyright for this article is retained by the author(s), with first publication rights granted to the journal.

This is an open-access article distributed under the terms and conditions of the Creative Commons Attribution license (http://creativecommons.org/licenses/by/3.0/). 